\title{
Electrocatalytic Oxidation of Hydrazine in Alkaline Media Promoted by Iron Tetrapyridinoporphyrazine Adsorbed on Graphite Surface
}

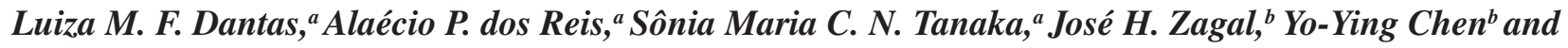 \\ Auro A. Tanaka*a \\ ${ }^{a}$ Departamento de Química, Centro de Ciências Exatas e Tecnologia, Universidade Federal do Maranhão, \\ 65085-580 São Luís-MA, Brazil \\ ${ }^{b}$ Departamento de Química de los Materiales, Facultad de Química y Biología, Universidad de Santiago de Chile, \\ Casilla 40, Correo 33, Santiago, Chile
}

\begin{abstract}
A oxidação eletrocatalítica de hidrazina foi estudada sobre um eletrodo de grafite pirolítico ordinário modificado com tetrapiridinoporfirazina de ferro (FeTPyPz) com as técnicas de voltametria cíclica e de eletrodo de disco rotatório. Análise dos voltamogramas registrados a diferentes velocidades de varredura do potencial e das curvas de polarização para diferentes velocidades de rotação do eletrodo mostraram que a reação de eletroxidação de hidrazina sobre FeTPyPz processa-se de acordo com um mecanismo envolvendo 4 elétrons e com a formação de $\mathrm{N}_{2}$ como principal produto. Os parâmetros cinéticos sugerem que a segunda etapa de transferência de carga é a etapa determinante da velocidade da reação. A atividade eletrocatalítica do complexo FeTPyPz depende do potencial formal do processo redox $\mathrm{Fe}(\mathrm{II}) / \mathrm{Fe}(\mathrm{I})$, que apresentou bom ajuste num gráfico do tipo vulcano formado por diferentes ftalocianinas de ferro, indicando que este potencial formal é um bom indicador da reatividade destes complexos.
\end{abstract}

The electrocatalytic oxidation of hydrazine was studied using an ordinary pyrolytic graphite electrode modified with iron tetrapyridinoporphyrazine complex (FeTPyPz), employing cyclic voltammetry and rotating disk electrode techniques. Analyses of the voltammograms recorded at different potential scan rates and the polarization curves at different electrode rotation rates showed that the reaction of electrooxidation of hydrazine on FeTPyPz occurs via 4-electrons with the formation of $\mathrm{N}_{2}$ as main product. The kinetic parameters suggest that the second electron transfer step is rate controlling. The activity of FeTPyPz depends on its $\mathrm{Fe}(\mathrm{II}) / \mathrm{Fe}(\mathrm{I})$ formal potential and fits well in a volcano plot that includes several iron phthalocyanines, indicating that such formal potential is a good reactivity index for these complexes.

Keywords: hydrazine oxidation, modified graphite electrode, iron tetrapyridinoporphyrazine, volcano plot

\section{Introduction}

The study of chemically modified electrodes has attracted considerable interest in the last decades as researchers attempt to exert more control over the chemical nature of the electrode surface. Molecules of known reactivity are then incorporated or confined on the electrode surface, acting as mediators for electron transfer reactions. Applications include electrocatalysis, electroanalysis, sensors and biosensors, as well as in electrochemical detection systems used in flow-injection

*e-mail: tanaka@ufma.br analysis or high performance liquid chromatography. ${ }^{1-30}$ One applicability of these electrodes refers to the oxidation and detection of hydrazine, an important chemical compound used in jet and rocket fuels and in the production of agricultural and textile chemicals, drugs, explosives, photographic developers, blowing agents used in the manufacture of foam rubber, and in the prevention of rusting in boilers and nuclear reactors. ${ }^{31}$ Furthermore, the detection of hydrazine and its derivatives is very important in pharmacology due to the recognition as carcinogenic and hepatotoxic substances. ${ }^{31,32}$

In order to reduce the typically large overpotentials and improve the kinetics of the direct oxidation of hydrazine 
at most conventional electrodes, carbon, graphite and gold electrodes modified with metallophthalocyanines and metalloporphyrins have attracted special attention. ${ }^{1,20,30,33}$ In addition, the effect of substituents on the ligand on the catalytic activity of metallophthalocyanines for the oxidation of hydrazine has been investigated for cobalt and iron derivatives. ${ }^{34,35}$ It has been found that as the electronwithdrawing power of the substituents increases, activity also increases, but only up to some point. After this, the activity decreases. So when activity, measured as current at constant potential is plotted versus the $\mathrm{M}(\mathrm{II}) / \mathrm{M}(\mathrm{I})$ formal potential of the complex, or versus the sum of the Hammett parameters of the substituents on the ligand, a volcano plot is obtained. This implies that the $\mathrm{M}(\mathrm{II}) / \mathrm{M}(\mathrm{I})$ formal potential of the complex needs to be located in a rather narrow potential window to achieve maximum activity for the reaction. ${ }^{34,35}$

In this work, an ordinary pyrolytic graphite (OPG) electrode was modified with iron tetrapyridinoporphyrazine (FeTPyPz) and its activity was investigated for the oxidation of hydrazine in alkaline media. The activity of this iron complex was compared with those of substituted and unsubstituted iron phthalocyanines reported in the literature. $^{35}$

\section{Experimental}

All solutions were prepared with distilled water purified in a Milli-Q Academic system from Millipore S.A. All reagents were Merck $^{\circledR}$ analytical grade and used without further purification. Iron tetrapyridinoporphyrazine (FeTPyPz) was synthesized and purified as previously reported. ${ }^{36}$ Prior to any electrochemical measurements, the electrolytic solution was saturated with White Martins 4.6 analytical grade argon gas. Experiments were carried out in $0.1 \mathrm{~mol} \mathrm{~L}^{-1} \mathrm{NaOH}$ in water.

The experiments were performed in a conventional electrochemical cell with three compartments. A disk of ordinary pyrolytic graphite (OPG) from Union Carbide, geometrical area of $c a .0 .4 \mathrm{~cm}^{2}$, mounted in Teflon, and a saturated calomel electrode (SCE) served as working and reference electrodes, respectively. All potentials, unless specified, are referred to this reference electrode. A platinum foil (geometrical area of $c a .2 \mathrm{~cm}^{2}$ ) was used as auxiliary electrode.

The OPG working electrode was first polished with 2000 grit emery paper, rinsed with purified water, sonicated in water for $2 \mathrm{~min}$ and rinsed with purified water several times. After drying at room temperature, the OPG surface was immersed in an air-saturated solution containing $2.0 \times 10^{-4} \mathrm{~mol} \mathrm{~L}^{-1} \mathrm{FeTPyPz}$ in $1.0 \mathrm{~mol} \mathrm{~L}^{-1} \mathrm{H}_{2} \mathrm{SO}_{4}$ solution and the electrode was rotated at $100 \mathrm{rpm}$ for different adsorption times. Finally, the electrode was thoroughly rinsed with purified water, in order to remove any excess of the complex, and introduced into the electrochemical cell containing the electrolyte solution. The electrochemical measurements were performed with a BAS CV-50W potentiostat from Bioanalytical System and the electrode rotation rate was controlled by an AFASR rotator from Pine Instruments Co.

\section{Results and Discussion}

\section{Characterization of the FeTPyPz modified electrodes}

Figure 1A shows the cyclic voltammogram of the unmodified OPG electrode (dashed line) in $0.1 \mathrm{~mol} \mathrm{~L}^{-1}$ $\mathrm{NaOH}$ solutions. The absence of voltammetric peaks indicated that the currents are purely of capacitive nature and not involving charge transfer. On the other hand, after modification with FeTPyPz (solid line), two well-defined voltammetric peaks, located at $c a .0 .35 \mathrm{~V}$ (peak 1) and ca. -0.05 V vs. SCE (peak 2), were observed. According to early work, ${ }^{36}$ these peaks can be associated to the $\mathrm{Fe}(\mathrm{II}) \mathrm{TPyPz} / \mathrm{Fe}(\mathrm{I}) \mathrm{TPyPz}$ and $\mathrm{Fe}(\mathrm{III}) \mathrm{TPyPz} / \mathrm{Fe}$ (II) TPyPz reversible redox processes, respectively. Similar assignments have been also made for a glassy carbon electrode modified with iron tetraaminophthalocyanine and several substituted iron phthalocyanines adsorbed on OPG. ${ }^{21,35,37}$

In order to establish an immersion time for modification of the OPG surface with FeTPyPz, the charge associated with the voltammetric peak 2 was plotted versus the immersion time $(\mathrm{t} / \mathrm{min})$ of the electrode surface in the FeTPyPz solution. Figure 1B shows that immersion time higher than $5 \mathrm{~min}$ is sufficient to reach the maximum charge value associated with FeTPyPz adsorbed species. Thus, 10 min was chosen as the modification time of the OPG surface with FeTPyPz.

Analyses of the cyclic voltammograms recorded at different potential scan rates showed that the peak currents in Figure 1A are directly proportional to the potential scan rate over the range investigated (50 to $400 \mathrm{mV} \mathrm{s}^{-1}$ ), the anodic $\left(E_{p a}\right)$ and cathodic $\left(E_{p c}\right)$ potential peak separations $\left(\Delta E_{p}=E_{p a}-E_{p c}\right)$ are very small ( $c a .10 \mathrm{mV}$ for the highest scan rate) and the anodic $\left(I_{p a}\right)$ and cathodic $\left(I_{p c}\right)$ current peak ratio $\left(I_{p d} / I_{p c}\right)$ approximately unity. These observations indicated that the redox process is reversible and involves only adsorbed species. ${ }^{27,37}$ Based on these information, the amount of adsorbed complex $\left.\Gamma(\mathrm{mol} \mathrm{cm})^{-2}\right)$ on the electrode surface could be calculated from the following equation: ${ }^{36,38}$ 

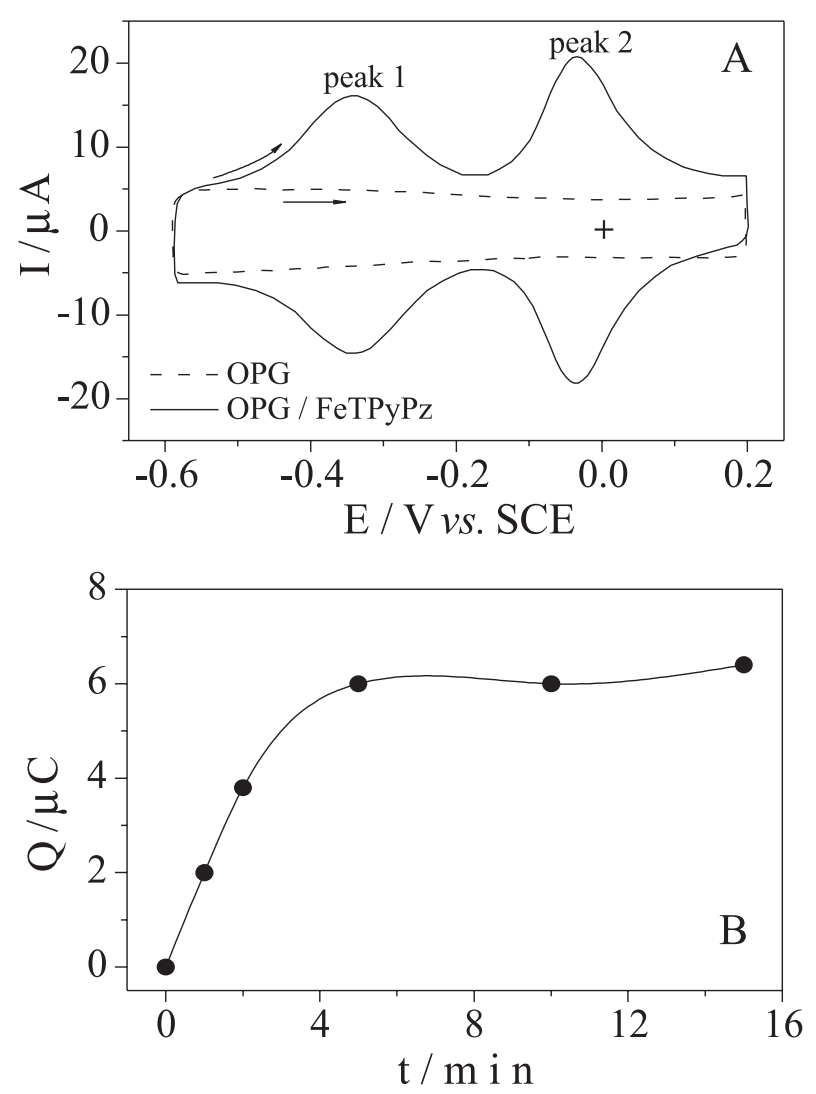

Figure 1. A) Cyclic voltammograms of the OPG electrode before (dashed line) and after adsorption of FeTPyPz (solid line) in $0.1 \mathrm{~mol} \mathrm{~L}^{-1} \mathrm{NaOH}$ solution, saturated with argon gas, $\mathrm{v}=200 \mathrm{mV} \mathrm{s}^{-1}, \mathrm{~T}=25^{\circ} \mathrm{C}$; B) Plot of the charge under peak $2(\mathrm{Q} / \mu \mathrm{C}) v s$. adsorption time $(\mathrm{t} / \mathrm{min})$ of the $\mathrm{OPG}$ electrode in a $\mathrm{H}_{2} \mathrm{SO}_{4} 1.0 \mathrm{~mol} \mathrm{~L}^{-1}$ solution containing $2.0 \times 10^{-4} \mathrm{~mol} \mathrm{~L}^{-1}$ FeTPyPz.

$I_{P}=\frac{n^{2} F^{2} A \mathrm{v}}{4 R T} \Gamma$

where $I_{P}(A)$ is the peak current; $\mathrm{v}\left(V s^{-1}\right)$ the potential scan rate; $A\left(\mathrm{~cm}^{2}\right)$ the electrode area; $n$ the number of electrons involved in the redox process and the other symbols have their usual meanings. Thus, $\Gamma$ was estimated as approximately $2.0 \times 10^{-10} \mathrm{~mol} \mathrm{~cm}{ }^{-2}$, which is close to the values $1.74 \times 10^{-10} \mathrm{~mol} \mathrm{~cm} \mathrm{~cm}^{-2}$ previously reported. ${ }^{36}$

\section{Electrocatalytic oxidation of hydrazine on $\mathrm{FeTPyPz}$}

\section{Voltammetric measurements}

Figure 2A shows the cyclic voltammograms recorded at different potential scan rates for the oxidation of hydrazine on the OPG electrode modified with FeTPyPz in $0.1 \mathrm{~mol} \mathrm{~L}^{-1} \mathrm{NaOH}$ solutions, saturated with argon gas. A cyclic voltammogram of the unmodified OPG electrode recorded at $50 \mathrm{mV} \mathrm{s}^{-1}$ under similar conditions was also included (curve a) for comparison. This figure clearly shows that hydrazine oxidation currents were not observed on the bare electrode and modification with FeTPyPz results in the onset of oxidation currents at potentials near $-0.55 \mathrm{~V}$. Furthermore, a comparison of Figure 1A and Figure 2A indicated that the hydrazine oxidation reaction on $\mathrm{FeTPyPz}$ modified electrodes begins at potentials close to the formal potential of the $\mathrm{Fe}(\mathrm{I}) \mathrm{TPyPz} / \mathrm{Fe}(\mathrm{II}) \mathrm{TPyPz}$ redox process, showing that the electrocatalytic activity of the complex can be associated to the metal center..$^{20,35,36}$

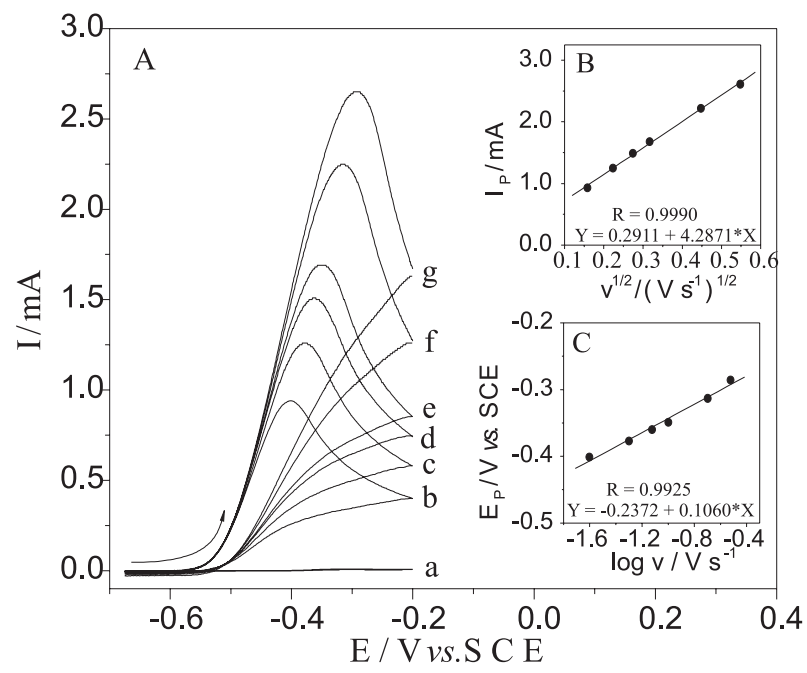

Figure 2. A) Cyclic voltammetric responses of a bare OPG electrode (curve a) and a FeTPyPz modified OPG electrode with scan rate (v) in $0.1 \mathrm{~mol} \mathrm{~L}{ }^{-1} \mathrm{NaOH}$ solution containing $5.0 \times 10^{-3} \mathrm{~mol} \mathrm{~L}^{-1} \mathrm{~N}_{2} \mathrm{H}_{4}$, saturated with argon gas. v: (a) 50; (b) 25; (c) 50; (d) 75; (e) 100; (f) 200 and (g) $300 \mathrm{mV} \mathrm{s}^{-1}$. B) Plot of $\mathrm{I}_{\mathrm{p}}$ versus square root of scan rate for $\mathrm{N}_{2} \mathrm{H}_{4}$ oxidation on FeTPyPz/OPG electrode. C) Plot of $\mathrm{E}_{\mathrm{P}}$ versus logarithm of scan rate for $\mathrm{N}_{2} \mathrm{H}_{4}$ oxidation on FeTPyPz/OPG electrode. $\mathrm{T}=25^{\circ} \mathrm{C}$.

Based on the facts that the voltammetric profile of the hydrazine oxidation reaction on the OPG electrode modified with FeTPyPz is similar to those associated with irreversible processes and the dependence of the peak currents $I_{P}(\mathrm{~A})$ with the square root of the electrode potential scan rate $\mathrm{v}^{1 / 2}\left(\mathrm{~V}^{1 / 2} \mathrm{~s}^{-1 / 2}\right)$ is linear (Figure $2 \mathrm{~B}$ ), the total number of electrons $n$ can be determined using the equation: ${ }^{39,40}$

$\mathrm{I}_{\mathrm{P}}=2.99 \times 10^{5} n\left[(1-\alpha) n_{o}\right]^{1 / 2} \mathrm{~A} C_{0} D_{0}^{1 / 2} \mathrm{v}^{1 / 2}$

where $C_{0}$ is the reactant concentration in the bulk solution $\left(C_{N_{2} \mathrm{H}_{4}}=5.0 \times 10^{-3} \mathrm{~mol} \mathrm{~L}^{-1}\right) ; D_{0}$ the diffusion coefficient in solution $\left(D_{N_{2} H_{4}}=1.4 \times 10^{-5} \mathrm{~cm}^{2} \mathrm{~s}^{-1}\right) ;^{37} A$ the geometrical area of the electrode $\left(A=0.4 \mathrm{~cm}^{2}\right) ; n$ the total number of electrons involved in the oxidation of hydrazine, $n_{0}$ the number of electrons involved in the rate-determining and $\alpha$ the electron transfer coefficient, which can be determined by the linear dependence of peak potential $\mathrm{E}_{\mathrm{p}}$ with the logarithm of the potential scan rate $\mathrm{v}$ (Figure $2 \mathrm{C}$ ), according to: 
$E_{P}=k+\left[\frac{0.03}{\alpha n_{0}}\right] \log \mathrm{v}$

where $k$ is a constant. From equations 2 and 3 and the slopes extracted from Figure $2 \mathrm{~B}$ and Figure $2 \mathrm{C}$ and assuming $n_{o}=1$, the values of $\alpha$ and $n$ were calculated as being 0.3 and 3.7 , respectively. Therefore, the voltammetric data indicates that the hydrazine oxidation reaction on the OPG electrode modified with FeTPyPz in alkaline media $(\mathrm{pH}=13.0)$ involves 4 electrons per hydrazine molecule with formation of nitrogen as main product, i.e.:

$\mathrm{N}_{2} \mathrm{H}_{4}+4 \mathrm{OH}^{-} \rightarrow \mathrm{N}_{2}+4 \mathrm{H}_{2} \mathrm{O}+4 e^{-}$

Analyses of the cyclic voltammograms recorded for the hydrazine oxidation reaction on the OPG electrode modified with FeTPyPz, in $0.1 \mathrm{~mol} \mathrm{~L}^{-1} \mathrm{NaOH}$ solutions containing different concentrations of hydrazine, showed a linear dependence between $\log \mathrm{I}_{\mathrm{P}}$ and $\log \left[\mathrm{N}_{2} \mathrm{H}_{4}\right]$ (Figure 3 ) with a slope approximately equal to 1 , which indicated that the reaction is first order with respect to hydrazine in solution. A similar reaction order has been also reported in studies involving the oxidation of hydrazine on glassy carbon electrodes modified with chlorogenic acid, iron tetraaminophthalocyanine and iron tetrasulfonated phthalocyanine..$^{37,41,42}$

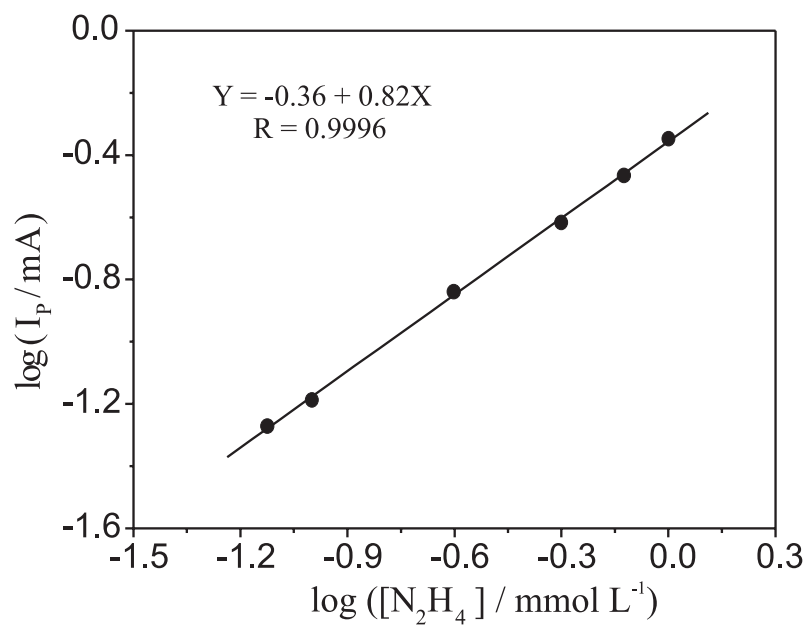

Figure 3. Plot of $\log \mathrm{I}_{\mathrm{p}}$ versus logarithm of hydrazine concentration.

Multiple cycling of the FeTPyPz/OPG surface in $0.1 \mathrm{~mol} \mathrm{~L}^{-1} \mathrm{NaOH}$ solutions in this regime provides a stable surface whose current remains constant. However, the electrocatalytic activity of FeTPyPz for hydrazine oxidation was observed to decrease significantly at solutions with $\mathrm{pH}$ lower than 12 and unfortunately it was not possible to obtain useful electrocatalytic data due to low currents and lack of well defined limiting currents in the rotating disk experiments.

\section{Rotating disk electrode measurements}

Polarization curves recorded at different disk electrode rotation rates for the oxidation of hydrazine on $\mathrm{FeTPyPz}$ in $0.1 \mathrm{~mol} \mathrm{~L}^{-1} \mathrm{NaOH}$ solution containing $5.0 \times 10^{-3} \mathrm{~mol} \mathrm{~L}^{-1}$ $\mathrm{N}_{2} \mathrm{H}_{4}$ are shown in Figure 4A. These curves were analyzed according to the characteristics of a first-order irreversible reaction controlled by diffusion, where the current $I(\mathrm{~A})$ is given by the Koutecky-Levich equation: ${ }^{21,38}$

$\frac{1}{I}=\frac{1}{I_{K}}+\frac{1}{I_{D}}$

where $I_{K}(\mathrm{~A})$ and $I_{D}(\mathrm{~A})$ represents the kinetic and diffusion controlled currents, respectively, with

$$
I_{D}=\left(0.62 n F A D_{0}^{2 / 3} C_{0} v^{-1 / 6}\right) f^{1 / 2}=B f^{1 / 2}
$$

where $D_{0}$ is the diffusion coefficient $\left(D_{N_{2} H_{4}}=1.4 \times 10^{-5} \mathrm{~cm}^{2} \mathrm{~s}^{-1}\right),{ }^{37}$ $C_{0}$ the reactant concentration in the bulk solution $\left(C_{N_{2} H_{4}}=5.0 \times 10^{-3} \mathrm{~mol} \mathrm{~L}^{-1}\right), v$ the solution kinematic viscosity $\left(\mathrm{v}=1.02 \times 10^{-2} \mathrm{~cm}^{2} \mathrm{~s}^{-1},{ }^{37,41,43} A\right.$ the electrode geometrical area $\left(A_{O P G}=0.4 \mathrm{~cm}^{2}\right), n$ the number of electrons transferred/reactant molecule, $f$ is the electrode rotation rate in radians $\mathrm{s}^{-1}$ and the other terms have their usual meanings. According to equations 5 and 6, a plot of $I^{-1}$ vs. $f^{-1 / 2}$ (Koutecky-Levich plot) should be linear with an angular coefficient of 1/B, as shown in Figure 4B for a fixed potencial of $-0.25 \mathrm{~V}$. Parallel lines were also observed for other potentials, which indicates a first order kinetics with respect to hydrazine in solution and a constant value of $n$ over the potential range investigated. A value of $n$ ca. 4 could be also concluded from the parallellism observed between the experimental line in Figure 4B (solid line) and the theoretical one expected for the reaction occurring under pure diffusion control with $n=4$ in equation 6 (dashed line). A Tafel plot was obtained from the rotating disk polarization curve recorded at 1600 rpm (Figure 4C) and the calculated slope of aproximately $45 \mathrm{mV} /$ decade suggested the second electron transfer as the rate determining step for the hydrazine oxidation reaction on the OPG electrode modified with FeTPyPz. ${ }^{20,37,42,44,45}$

Based on the voltammetry and rotating disk electrode data, a possible mechanism that can be proposed for the hydrazine oxidation reaction in alkaline media catalyzed by FeTPyPz adsorbed on the OPG surface involves the following steps:

$[\mathrm{TPyPz}-\mathrm{Fe}(\mathrm{I})]^{-} \rightarrow[\mathrm{TPyPz}-\mathrm{Fe}(\mathrm{II})]+2 e^{-}$ 


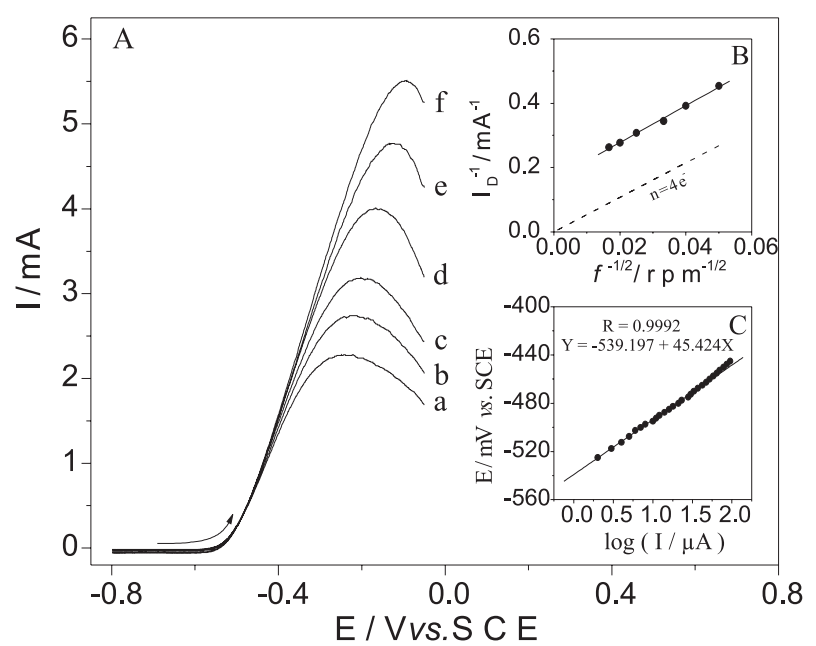

Figure 4. A) Rotating disk polarization curves recorded at different FeTPyPz/OPG electrode rotation rates in $0.1 \mathrm{~mol} \mathrm{~L}^{-1} \mathrm{NaOH}$ solution containing $5.0 \times 10^{-3} \mathrm{~mol} \mathrm{~L}^{-1} \mathrm{~N}_{2} \mathrm{H}_{4}$. Electrode rotation rates: (a) 400 ; (b) 625 ; (c) 900 ; (d) 1600; (e) 2500 and (f) $3600 \mathrm{rpm} . \mathrm{v}=20 \mathrm{mV} \mathrm{s}^{-1}$. B) Experimental (solid line) and theoretical (dashed line) KouteckyLevich plots for the $\mathrm{N}_{2} \mathrm{H}_{4}$ oxidation on FeTPyPz/OPG modified electrode. C) Tafel plot for $\mathrm{N}_{2} \mathrm{H}_{4}$ oxidation on FeTPyPz/OPG modified electrode.

$$
\begin{aligned}
& {[\mathrm{TPyPz}-\mathrm{Fe}(\mathrm{II})]+\mathrm{N}_{2} \mathrm{H}_{4}+\mathrm{OH}^{-} \rightarrow} \\
& {[\mathrm{TPyPz}-\mathrm{Fe}(\mathrm{I})]^{-}\left(\mathrm{N}_{2} \mathrm{H}_{3}\right)^{+}+\mathrm{H}_{2} \mathrm{O}+e^{-}}
\end{aligned}
$$

$$
\begin{aligned}
{[\mathrm{TPyPz}-\mathrm{Fe}(\mathrm{I})]^{-}\left(\mathrm{N}_{2} \mathrm{H}_{3}\right)^{+}+\mathrm{OH}^{-} \stackrel{\text { rds }}{\rightarrow} } \\
{[\mathrm{Fe}(\mathrm{II}) \mathrm{TPyPz}]+\bullet \mathrm{N}_{2} \mathrm{H}_{2}+\mathrm{H}_{2} \mathrm{O}+e^{-} }
\end{aligned}
$$

- $\mathrm{N}_{2} \mathrm{H}_{2}+2 \mathrm{OH}^{-} \rightarrow \mathrm{N}_{2}+2 \mathrm{H}_{2} \mathrm{O}+2 e^{-}$

This mechanism is compatible with the facts that: $i$ ) the reaction is mediated by the $\mathrm{Fe}(\mathrm{II}) \mathrm{TPyPz} / \mathrm{Fe}(\mathrm{I}) \mathrm{TPyPz}$ redox process, $i i)$ the reaction is first-order with respect to hydrazine iii) a second electron transfer step is the rate determining step ( $r d s)$ and iv) molecular nitrogen is the reaction product.

It is interesting to note that the peak potentials of the cyclic voltammograms for the hydrazine oxidation reaction on FeTPyPz shift to more positive potentials with the increase in the potential scan rate (Figure 2C), which suggests kinetic limitations. In addition, the peak currents increase linearly with the square root of the scan rate (Figure 2B), which indicates that, at sufficient overpotentials, the reaction is controlled by diffusion. Furthermore, the polarization curves (Figure 4) show that the oxidation currents increase as the potential becomes more positive and reaches maximum values, without the definition of a "plateau", as expected for reactions controlled by diffusion. The decay of the currents after the maximum could be attributed to the formation of $\mathrm{N}_{2}$ bubbles on the electrode surface and/or the passivation of the surface by the adsorption of an intermediate on the catalytic active sites. A plot of these maximum currents as a function of the square root of the electrode rotation rate (Figure 5) reveals significant deviation of the linear behavior (dashed line) expected from equation 6 , which also indicates kinetic and not mass transport limitation or mixed control.

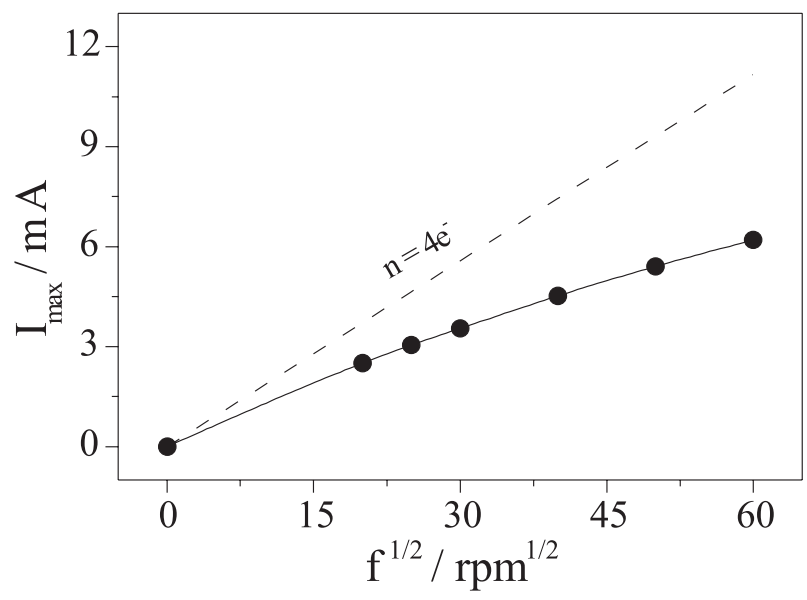

Figure 5. Levich plot for $\mathrm{N}_{2} \mathrm{H}_{4}$ oxidation on FeTPyPz/OPG modified electrode in $0.1 \mathrm{~mol} \mathrm{~L}^{-1} \mathrm{NaOH}$ containing $5.0 \times 10^{-3} \mathrm{~mol} \mathrm{~L}^{-1} \mathrm{~N}_{2} \mathrm{H}_{4}$. Data taken from Figure 4A.

The redox potential $\mathrm{M}(\mathrm{II}) /(\mathrm{I})$ has been found to be an important reactivity index for these complexes ${ }^{20,21,34,35,40,46-49} \mathrm{so}$ it is interesting to compare the catalytic activity of FeTPyPz with that of similar complexes like iron phthalocyanines and derivatives using the redox potential. In previous studies, it has been observed that the electrocatalytic activity, measured as current (at constant potential) divided by the surface concentration of catalyst and plotted versus the Fe(II)/(I) redox potential of the complex gives a volcano-shaped curve. Figure 6 illustrates the volcano plot that compares the relative activities of the different Fe complexes: iron octametoxyphthalocyanine (FeOMeOPc), iron tetraaminophthalocyanine (FeTAPc), iron tetracarboxyphthalocyanine $(\mathrm{FeTcPc})$, iron phthalocyanine (FePc), iron tetrasulfonated phthalocyanine (FeTsPc), iron tetranitrophthalocyanine (FeTNPc) and iron hexadecachlorophthalocyanine $\left(\mathrm{FePcCl}_{16}\right) \cdot{ }^{35}$ Currents have been divided by the surface concentration of the catalysts and by the hydrazine concentration to make our results comparable to those obtained in the literature. The activity of FeTPyPz fits in one of the branches of the volcano, which shows that the $\mathrm{Fe}(\mathrm{II}) /(\mathrm{I})$ redox potential is a good reactivity index for this complex, even though FeTPyPz is not a phthalocyanine as the other complexes included in Figure 6. The volcano plot of Figure 6 indicates that the activity of FeTPyPz could be improved by placing electron-donating groups on the ligand that could shift the $\mathrm{Fe}$ (II//I) formal potential to more negative values, approaching the maximum that occurs at 
ca. -0.65 V. Correlations like that in Figure 6 are well known in electrocatalysis when the catalytic activity is plotted versus some parameter that accounts for the degree of interaction of the reacting molecule with the active site. ${ }^{50,51} \mathrm{~A}$ parameter that accounts for this is $\Delta \mathrm{G}^{\circ}$ of adsorption of $\mathrm{N}_{2} \mathrm{H}_{4}$ on the $\mathrm{Fe}$ sites. This corresponds to the thermodynamics of step 7 in the reaction scheme. Step 7 becomes more favorable (more negative $\Delta \mathrm{G}^{\circ}$ ) when $\mathrm{Fe}(\mathrm{II})$ is more easily reduced. With this in mind, one would expect that step 7 becomes more favorable as the $\mathrm{Fe}(\mathrm{II} /(\mathrm{I})$ formal potential becomes more positive. So more positive $\mathrm{Fe}(\mathrm{II} / \mathrm{I}$ ) formal potential should favor the reaction and this would correspond to the ascending portion of the volcano correlation in Figure 6. Maximum activity should be observed when $\Delta \mathrm{G}^{\circ}=0.4^{49,50}$ This would correspond to a surface coverage by the adduct [TpyPz-Fe(I)]- $\left(\mathrm{N}_{2} \mathrm{H}_{4}\right)^{+}$equal to 0.5 . Favoring step 7 beyond this point should decrease the activity since the surface would become gradually more covered by the adduct, decreasing the available free Fe sites for the reaction. This would correspond to the declining portion of the volcano in Figure 6. This is so because step 9 is rate determining and the adduct [TpyPz-Fe(I)]- $\left(\mathrm{N}_{2} \mathrm{H}_{4}\right)^{+}$would accumulate on the surface as the following step is slow. The data in Figure 6 clearly illustrates that to obtain the highest activity for the reaction, the $\mathrm{Fe}$ (II/(I) formal potential need to be "tuned" in a rather narrow potential window. This is very important when designing catalysts for this reaction and other reactions as well. ${ }^{49}$

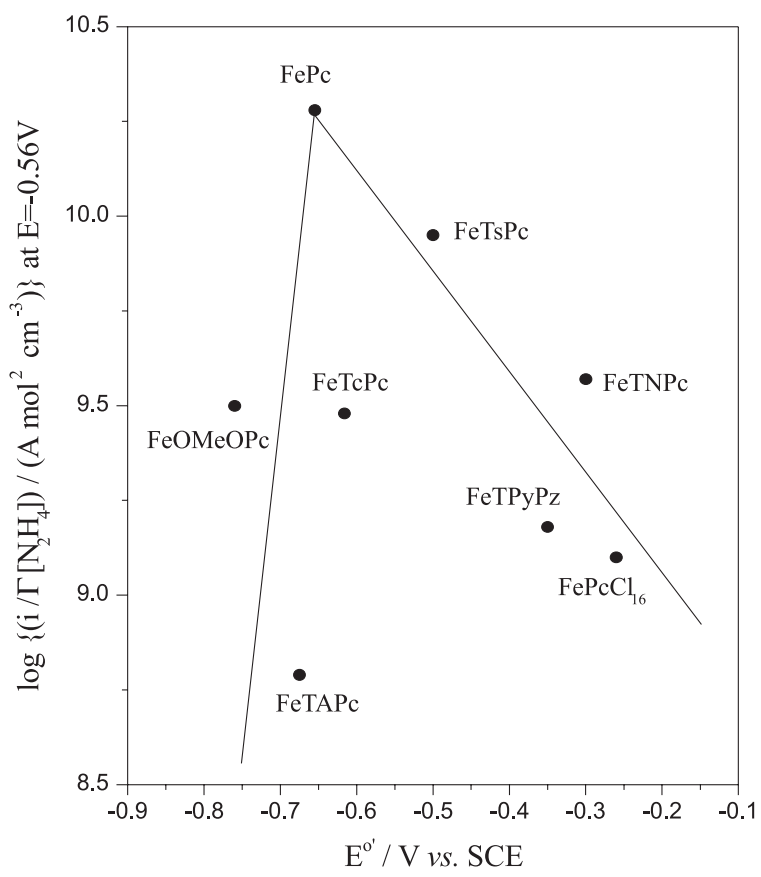

Figure 6. Volcano plot for the oxidation of hydrazine in $0.1 \mathrm{~mol} \mathrm{~L}^{-1} \mathrm{NaOH}$ on graphite modifed with several $\mathrm{Fe}$ macrocyclic complexes. Data for $\mathrm{Fe}$ phthalocyanines obtained from ref. 37.

\section{Conclusions}

The OPG electrode modified with FeTPyPz showed high catalytic activity for the oxidation of hydrazine oxidation in alkaline media. The Fe(II)TPyPz species are responsible for the electrochemical activity of the complex and the overall oxidation reaction proceeds via a four-electron mechanism. The reaction is first order with respect hydrazine in solution and producing molecular nitrogen as the main product of reaction. The Tafel slope, close to $0.045 \mathrm{~V} /$ decade, suggested that the second charge transfer step is rate determining. Finally, the $\mathrm{Fe}(\mathrm{II}) / \mathrm{Fe}(\mathrm{I})$ redox potential of FeTPyPz is a good reactivity index for hydrazine oxidation since the activity of this complex fits well in a volcano correlation that includes several Fe phthalocyanines adsorbed on graphite, for which the electrocatalytic activity was measured under similar conditions to those used for FeTPyPz.

\section{Acknowledgments}

The authors gratefully acknowledge the financial supports from Conselho Nacional de Desenvolvimento Científico e Tecnológico (CNPq) and Financiadora de Estudos e Projeto (FINEP). J. Zagal is grateful to the support of project Fondecyt 1060030. L.M.F. Dantas and A.P. Reis are indebted to CAPES for the fellowships.

\section{References}

1. Zagal, J.; Bedioui, F.; Dodelet, J.P.; $N_{4}$-Macrocyclic Metal Complex, Springer, Heidelberg, 2006.

2. Chow, E.; Gooding, J.J.; Electroanal. 2006, 18, 1437.

3. Brugnera, M.F.; Santos, D.P.; Zanoni, M.V.B.; Eclet. Quim. 2006, 31, 63 .

4. Wang, J.; Electroanalysis 2005, 17, 7.

5. Ricci, F.; Palleschi, G.; Biosens. Bioelectron. 2005, 21, 389.

6. Gooding, J.J.; Electrochim. Acta 2005, 50, 3049.

7. Ricci, F.; Gonçalves, C.; Amine, A.; Gorton, L.; Palleschi, G.; Moscone, D.; Electroanalysis 2003, 15, 1204.

8. Zen, J.-M.; Kumar, A.S.; Tsai, D.-M.; Electroanalysis 2003, 15, 1073 .

9. Nyokong, T.; Vilakazi, S.; Talanta 2003, 61, 17.

10. Wang, J.; Talanta 2002, 56, 223.

11. Walcarius, A.; Electroanalysis 2001, 13, 701.

12. Biesaga, M.; Pyrzynska, K.; Trojanowicz, M.; Talanta 2000, 209.

13. Walcarius, A.; Anal. Chim. Acta 1999, 384, 1.

14. Lorenzo, E.; Pariente, F.; Hernández, L.; Tobalina, F.; Darder, M.; Wu, Q.; Maskus, M.; Abruña, H.D.; Biosens. Bioelectron. 1998, 13, 319. 
15. Bedioui, F.; Trevin, S.; Devynck, J.; Electroanalysis 1996, 8, 1085.

16. Ruzgas, T.; Csöregi, E.; Emnéus, J.; Gorton, L.; Marko-Varga, G.; Anal. Chim. Acta 1996, 330, 123.

17. Gorton, L.; Electroanalysis 1995, 7, 23.

18. Gilmartin, M.A.T.; Hart, J.P.; Analyst 1995, 120, 1029.

19. Budnikov, G.K.; Labuda, J.; Russ. Chem. Rev. 1992, 61, 816.

20. Zagal, J.; Coord. Chem. Rev. 1992, 119, 89.

21. Zagal, J.; Paez, J.; Tanaka, A.A.; Santos Junior, J.R.; Linkous, C.; J. Electroanal. Chem. 1992, 339, 13.

22. Cox, J.A.; Jaworski, R.; Kulesza, P.J.; Electroanalysis 1991, 3, 869.

23. Wang, J.; Electroanalysis 1991, 3, 255.

24. Wang, J.; Anal. Chim. Acta 1990, 234, 41.

25. Dong, S.; Wang, Y.; Electroanalysis 1989, 1, 99.

26. Abruña, H.D.; Coord. Chem. Rev. 1988, 86, 135.

27. Imisides, M.D.; Wallace, G.G.; Wilke, E.A.; Trends Anal. Chem. 1988, 7, 143.

28. Patriarche, G.J.; J. Pharm. Biom. Anal. 1986, 4, 789.

29. Murray, R.W. In Chemically Modified Electrodes in Electroanalytical Chemistry, A. J. Bard ed., Marcel Dekker, New York, 1984, v.13, p. 191.

30. Tarasevich, M.R.; Radyushkina, K.A.; Russ. Chem. Rev. 1980, 49, 718 .

31. Schmidt, E.W.; Hydrazine and its Derivatives: Preparation, Properties, Applications, Wiley Interscience: New Jersey, 2001.

32. Toth, B.; Hydrazines and Câncer: A Guidebook on the Carcinogenic Activities of Hydrazines, Related Chemicals and Hydrazine Containing Natural Products, CRC Press: Boca Raton, 2000.

33. Ozoemena, K.I.; Nyokong, T.; Talanta 2005, 67, 162.

34. Geraldo, D.; Linares, C.; Chen, Y-Y.; Ureta-Zañartu, S.; Zagal, J. H.; Electrochem. Comm. 2002, 4, 182.

35. Linares, C.; Geraldo, D.; Paez, M.; Zagal, J. H.; J. Solid. State Electrochem. 2003, 7, 626.
36. Tanaka, A.A.; Fierro, C.; Scherson, D.A.; Yeager, E.; Mater. Chem. Phys. 1989, 22, 431.

37. Ardiles, P.; Trollund, E.; Isaacs, M.; Armijo, F.; Canales, J. C.; Aguirre, M. J.; Canales, M. J.; J. Mol. Catal A: Chem. 2001, $165,169$.

38. Bard, A. J.; Faulkner, L. R.; Electrochemical Methods: Fundamentals and Applications, $2^{\text {nd }}$ ed., Wiley \& Sons: New York, 2001.

39. Zhang, J.; Tse, Y. H.; Pietro, W. J.; Lever, A. B. P.; J. Electroanal. Chem. 1996, 406, 203.

40. Razmi-Nerbin, H.; Pournaghi-Azar, M. H.; J. Solid State Electrochem. 2002, 6, 126.

41. Golabi, S. M.; Zare, R.; J. Electroanal. Chem. 1999, 465, 168.

42. Zagal, J.H.; Ureta-Zañartu, S.; J. Electrochem. Soc. 1982, 129, 2249.

43. Zhang, J.; Pietro, W. J.; Lever, A. B. P.; J. Electroanal. Chem. 1996, 403, 93.

44. Zagal, J.H.; Muñoz, E.; Ureta-Zañartu, S.; Electrochim. Acta 1982, 27, 1373.

45. Zagal, J. H.; Lira, S.; Ureta-Zañartu, S.; J. Electroanal. Chem. 1986, 210, 95.

46. Zagal, J. H.; Paéz, M. A.; Electrochim. Acta 1007, 42, 3477.

47. Zagal, J. H.; J. Electroanal. Chem. 1980, 109, 389.

48. Pournaghi-Azar, M.H.; Sabzi, R.; J. Electroanal. Chem. 2003, $543,115$.

49. Bedioui, F.; Griveau, S.; Nyokong, T.; Appleby, A.J.; Caro, C.A.; Gulppi, M.; Ochoa G.; Zagal, J.H.; Phys. Chem. Chem. Phys. 2007, 9, 3383.

50. Appleby A.J. In Modern Aspects of Electrochemistry; Conway, B.; Bockris, J. O’M., eds., Plenum Press: New York, 1974, vol. 9, p. 369

51. M. M. Jaksic, M.M.; Electrochim. Acta 2000, 45, 4085.

Received: September 30, 2007

Web Release Date: April 23, 2008 